If the patient is allowed fluid by mouth, it should be given by the feeder between times of aspiration.

Aspiration is performed at regular intervals either every hour or half-hour according to instructions.

The aspirated material must always be saved for inspection.

2. Continuous Suction: A study of the diagram (Fig. 2) will explain the work of the apparatus, and particular attention must be paid to the following points:-

I. The reservoir A must never be allowed to become empty.

2. The end of the tubing in bottle $B$ must be below the level of the water.

3. The clips $\mathrm{D}$ and $\mathrm{E}$ must be clamped before and during the changing of the bottles $\mathrm{A}$ and B. They are then released to re-commence suction.
4. If the apparatus does not appear to be working, the clips should be clamped, the apparatus disconnected from the gastric tube and some water injected down the tube to make sure that it is patent.

The Time for Removal of the Tube: The tube is removed under the Doctor's instructions. In cases of intestinal obstruction this is usually after the patient has had one bowel action, and has passed flatus on at least two occasions. After operations on the stomach, the tube is removed when the aspirated contents appear clear and contain bile.

Vomiting: If a patient who is undergoing gastrointestinal suction vomits, it indicates that there is some fault in the procedure, and is a reflection on the management of the suction. Every effort should be made to discover and correct the fault.

\title{
RECENT DEVELOPMENTS IN WOUND ANTISEPTICS
}

\section{By H. E. Dale}

During recent years a considerable amount of work has been carried out with the object of finding a non-toxic antiseptic which would be effective against all the bacteria likely to be present in wounds. From I939 onwards sulphonamides, especially sulphanilamide, have been used extensively by local application in the prevention and control of wound infection, and they are undoubtedly effective bacteriostatic agents. Their action is, however, inhibited by pus and necrotic tissue, and they are ineffective against some organisms. Penicillin has and will be used extensively, and may well replace many antiseptics, but it is not effective against gram-negative organisms such as Ps. pyocyanea and Proteus and supplies are at present restricted.

\section{Acridines}

The acridines or flavines, as they have been called, were introduced by Browning in I9I7, and recent work on their properties and methods of application has brought to light many interesting facts. For some time acriflavine was considered to be the most suitable acridine for use as an antiseptic, but in I94I proflavine sulphate was included in the 4th Addendum to the British Pharmacopoeia. Acriflavine is much more soluble in water than the other acridines, and it would appear that it was selected primarily for this reason as the bacteriostatic powers of acriflavine, neutral acriflavine (or euflavine) and proflavine against various organisms are approximately the same. In I934 acriflavine was shown to be a mixture of the hydrochlorides of $2: 8$-diaminoro-methylacridinium chloride and $2: 8$-diaminoacridine, and neutral acriflavine a mixture of 2:8-diamino-ro-methylacridinium chloride and 2:8-diaminoacridine hydrochloride. Proflavine is however, not a mixture but a simple salt2 : 8-diaminoacridine sulphate. It is the precursor, of acriflavine and neutral acriflavine and is therefore simpler to manufacture.

In I936 Albert Linnell and others began intensive investigations on the acridine series. They prepared all the possible aminoacridines and investigated the relation between chemical constitution and activity. They found that amino groups in positions 2,3 , or 5 increased the activity of the acridine molecule and gave compounds of high bacteriostatic activity. 2:7-diaminoacridine and 5-aminoacridine were considered to be the best of the series.

It is well known that chlorophenols are considerably more active than the parent phenol, and experiments were also carried out to determine the effect of introducing chlorine into aminoacridines. New chloroacridines were prepared but 
they were less active than the aminoacridines and possessed no therapeutic advantages. 2-chloro-5aminoacridine was found to be most active, but also the most toxic and the 6- and 7-chloro-2aminoacridines were quite inactive.

Attention was again drawn to proflavine and the two new acridines $2: 7$-diaminoacridine and 5-aminoacridine, when Russell and Falconer (I940) showed that buffered isotonic solutions of proflavine sulphate with a $\mathrm{pH}$ approaching neutrality could safely be applied to the surface of a rabbit's brain. They found that both acriflavine and neutral acriflavine caused damage, but the newer compounds 2 : 7-diaminoacridine and 5-aminoacridine did not. The surprising fact that isotonic solutions of proflavine could be applied to such delicate tissues as brain tissues stimulated greater interest in this compound and also in the newer acridines $2: 7$-diaminoacridine and 5-aminoacridine. Clinical reports on the new acridines have been published in this country and in Australia confirming their value as non-toxic antiseptics, but it is difficult to assess how these new compounds differ in their bacteriological action from proflavine. It has been suggested that the divergence of opinion on their relative toxicity to leucocytes and action against certain bacteria may be dependent upon the methods employed by different workers. Generally, it can be said they do not differ very much in their action from that of proflavine against most organisms. 5-aminoacridine, unlike most other acridine antiseptics, does not stain the skin or fabrics. It is a yellow compound, but the yellow colour may be removed easily by washing with water. As acridine stains are usually very difficult to remove, this is a decided advantage. Solutions of proflavine sulphate deposit on exposure to light, but solutions of 5 -aminoacridine hydrochloride are stable. 2 : 7-diaminoacridine hydrochloride and proflavine sulphate are stated to be .ess toxic than 5-aminoacridine hydrochloride and also possibly effective against Ps. pyocyanea and Proteus.

Berry (I94I) investigated the bacteriostatic values of the two components of acriflavine against various organisms and found that mixtures possessed no greater bacteriostatic power than either compound. He suggested that the neutral hydrochloride of $2: 8$-diaminoacridine, i.e. proflavine monohydrochloride, would be the best acridine to use.

Albert (I943) described several salts of proflavine, the more important being the monohydrochloride and neutral sulphate, orange to red powders giving solutions which are nearly neutral. They may replace the more acid proflavine sulphate which is usually employed.
More recently Albert et al. (I945) in a general survey of the acridine series have described three new drugs, I : 9-dimethyl-proflavine, 5-amino-Imethylacridine and 2-nitro-5-aminoacridine.

Bacteriological tests showed that I : 9-dimethylproflavine is approximately five times as potent as proflavine against gram-positive and twice as potent against gram-negative organisms without any increase in toxicity.

5-amino-I-methylacridine is non-staining, less toxic and more active than 5 -aminoacridine.

The outstanding property of 2-nitro-5-aminoacridine is its marked anti-streptococcal action suggesting a sphere of usefulness in the treatment of haemolytic streptococcal infections and prophylactically in obstetrics.

\section{Relative Toxicity}

Selbie and McIntosh (I943), carried out experimental work on the action of antiseptics on muscle and connective tissue. The assessment of toxicity by this method was designed to avoid reactions other than those arising from the toxicity of the substance to be tested, and to simulate as far as possible, in experimental animals, conditions likely to be found in wounds. A known quantity of the substance to be tested was dissolved in water, and $0 . I$ and 0.2 c.c. were injected into the thigh muscles of mice. The mice were killed after 3 days and it was found that any lesions were fully developed by that time. Any visible reactions were noted and the injected muscles were examined histologically. Proflavine sulphate produced approximately the same degree of muscle necrosis and connective tissue reaction as $2: 7$-diaminoacridine hvdrochloride and 5-aminoacridine hydrochloride, but the acridine bases were considerably more toxic than their acid salts, producing more necrosis and considerable cellular reaction. The toxicity of bases in pharmaceutical preparations was also determined and it was shown that many had a high degree of tissue toxicity. This work is not yet completed, but experiments carried out so far show how important it is to examine the bases used in ointments and other pharmaceutical preparations for their toxicity to tissues before use.

\section{Method of Application}

The acridines, until recently, were only applied to wounds in solution in water or saline, but it has now been shown that proflavine can safely be applied in powder form to infected wounds, provided small amounts only are employed. Suppurating wounds have been successfully treated 
with proflavine powder in amounts up to $0.5 \mathrm{gm}$., but in fresh wounds too much proflavine may cause some necrosis of healthy tissue.

Since no one drug has proved effective against all the organisms likely to be found in wounds it seemed likely that the best results would be achieved with a mixture of two or more drugs which complemented each other in their action. McIntosh and Selbie (I944) suggested a mixture of 99 parts sulphathiazole and one part proflavine sulphate known as S.P. Powder which has been extensively employed by the Army Medical Department for application to wounds. The proflavine is stated to enhance the anti-staphylococcal action of the sulphathiazole and at the same time affords protection against gram-negative organisms such as Ps. pyocyanea, Proteus and coliform bacilli. For the local treatment of wounds S.P. Powder is applied in the same manner as sulphanilamide and has given very good results.

\section{Sulphonamides}

With the introduction of the sulphonamides a demand quickly arose for ointments and creams. The most popular of these was a sulphanilamide cream with a water miscible base containing the antiseptic detergent cetyl trimethyl ammonium bromide (CTAB). This was known as the Glasgow No. 9 cream and was officially recommended in M.R.C. War Memorandum, No. Io, "The Medical Use of Sulphonamides" for the first-aid treatment of burns and scalds of slight and moderate severity. Owing to the great variation of the solubility of sulphanilamide with temperature, difficulty has been experienced in the preparation of satisfactory creams with water miscible bases, particularly on a manufacturing scale, and it is of interest to note that the formula of sulphanilamide cream has recently been altered to contain equal parts of sulphathiazole and sulphanilamide as described in the National War Formulary addendum I945.

Sulphanilamide creams made with bases containing water gradually crystallise and the product tends to develop a gritty texture. To overcome this a considerable amount of work has been carried out and it has been demonstrated that sulphanilamide and sulphathiazole may be combined to give a sulphanilamide-sulphathiazole compound. This preparation does not appear to offer any bacteriological advantages over its components, but on account of its physical properties and low solubility offers advantages in the production of water-containing creams which are free from tendency to develop crystals.

\section{Prollavine-Sulphathiazole (Flavazole)}

Recent investigations have shown that several sulphonamides are sufficiently acidic to unite with various aminoacridines to form definite compounds of the salt type, and ProflavineSulphathiazole (Flavazole), has been submitted to bacteriological, pharmacological and clinical investigation.

Fravezole has a solubility in water and normal saline of about I-2,500, I-250 in alcohol and is readily soluble in glycerin and acetone. The saturated solution is neutral or slightly alkaline ( $\mathrm{pH} 7 \cdot 0-7 \cdot 4)$.

\section{Bacteriological Results}

The action of Flavazole against certain gramnegative organisms indicated that it was in some respects superior to either sulphathiazole or proflavine sulphate respectively, or to mixtures of the two. Further bactericidal tests carried out by McIntosh, et al. (I945), confirmed that Flavazole was at least as efficient as either sulphathiazole or proflavine sulphate against all the organisms tested. Compared with sulphathiazole, Flavazole was three hundred to six hundred times more active against $\mathrm{Cl}$. welchii and $\mathrm{Cl}$. oedematiens, eight to sixteen times more active against $P$ s. pyocyanea, and sixteen to one hundred and twenty times more active against Proteus. Compared with proflavine sulphate, Flavazole was of equal value against most organisms, but was more active against Ps. pyocyanea and Proteus.

\section{Toxicity}

The maximum tolerated dose of Flavazole given by intramuscular injection into mice was $30 \mathrm{mg}$. for a $20 \mathrm{gm}$. mouse, whereas the maximum tolerated dose of proflavine sulphate was $1.5 \mathrm{mg}$. The local toxicity to muscle tissue of the two drugs had approximately the same relationship, but the difference was less by the intraperitoneal route, which was probably due to the low solubility (I : 2,500) of Flavazole.

\section{Pharmacological Results}

Tests carried out against anaerobic infections in mice showed that Flavazole lost none of the therapeutic value of its components against $\mathrm{Cl}$. welchii and $\mathrm{Cl}$. septicum infections. The following table shows the average days survived by the mice expressed as a percentage of three days when the experiments were terminated. The drugs were injected at the site of infection one hour after intramuscular inoculation of a washed suspension of organisms in 2.5 per cent calcium chloride solution. 
EFFICIENCY OF WOUND ANTISEPTICS

(Expressed in percentage survival rate)

$\begin{array}{llccc}\text { Flavazole } & & \text { Dose } & \text { Cl. welchii } & \text { Cl. septicum } \\ \text { Sulphathiazole } & \ldots & \text { Io mg. } & 90 & 90 \\ \text { Proflavine } & \text {. } & \text { 40 } \mathrm{mg} . & 7 & 90 \\ \text { Penicillin } & \text {. } & \text { 50 units } & 60 & 70 \\ \text { Control Mice } & \text {. } & - & \text { Ioo } & 60 \\ & - & 0 & 0\end{array}$

\section{Clinical Results}

The published clinical results on Flavazole are on over a hundred cases and the Flavazole was used as a compound powder containing 2 per cent Flavazole and 98 per cent Sulphathiazole. It has also been employed as a saturated aqueous solution $(I: 2,500)$. Further clinical trials are in progress. The cases treated were mainly open wounds which could be accurately observed clinically and bacteriologically. Many cases had been very heavily infected for a prolonged period, and treatment was successful in 50 per cent of cases, the success being estimated by the take of skin grafts or healing after various plastic operations.

In a number of cartilage grafts and rotation flaps in which no known infection was present, healing was achieved by first intention in every case. In a few cases where Compound Flavazole Powder was used twice daily, a dermatitis resulted. This cleared rapidly on discontinuing for fortyeight to seventy-two hours, and did not recur when smaller doses were used.

Pressure sores presented a very serious problem because of the loss of nerve supply and likelihood of contamination. In nine pressure sores heavily infected with pyogenic cocci and gram-negative bacilli, there was a great reduction of infection following the application of Compound Flavazole Powder, though complete elimination of bacteria was difficult owing to the unhealthy state of the tissues. Infection was, however, reduced and healing was promoted.

\section{Method of Application}

After a thorough cleansing of the wound, Compound Flavazole Powder should be dusted over the surface either from a sifter envelope or by means of an insufflator. On a clean, fresh wound, the amount applied should be just enough to give a slight dusting or frosting on the surface equivalent to $0.5 \mathrm{gm}$. for an area of 4 square niches. In old or suppurating wounds, more may be used. This treatment may be repeated daily without undue danger of unfavourable reactions.

It is interesting to note that penicillin may be mixed with Compound Flavazole Powder without any reduction in its activity, and that this addition enhances the activity of the powder, particularly against staphylococci.

Flavazole can also be used as a saturated solution in water or normal saline for the irrigation of infected wounds, as a bladder lavage, and as an antiseptic eyewash. Undiluted Flavazole must not be used on wounds.

\section{REFERENCES}

ALBERT, A. (1943), Pharm. J., 2, 87 .

ALBERT, A., and LINNELL, W.H. (1936), J.chem. Soc., 88.

ALBERT, A., RUBBO, S. D., GOLDACRE, R. J., DAVEY, M. E., and STONE, J. D. (1945), Brit. J. exp. Path., 26, 160.

BERRY, H. (I94I), Quart. J. Pharm., 14, 149 .

BROWNING, C. H., GULBRANSEN, R., KENNAWAY, E. L., and THORNTON, L. H. D. (1917), Brit.' med. J., 1, 73 .

MCINTOSH, J., and SELBIE, F. R.' (I944) Lancet, 1, 66 .

MCINTOSH, J., ROBINSON, R. H. M., SELBIE, F. R., REIDY, J. P., ELLIOTT BLAKE, H., and GUTTMANN, L. (I945), Lancet, $2,97$.

RUSSELL, D. S., and FALCONER, M. A. (1940), Brit. J. Surg., 28, 472. SELBIE, F. R., and MCINTOSH, J. (I943), J. Path. Bact., 55, 477.

\title{
HISTORY OF MEDICINE SECTION
}

\section{PRESERVING MINERAL WATERS}

\author{
A letter of 1735 from Stephen Hales, F.R.S.
}

The fashion for "taking the waters" was at its height in the mid-eighteenth century, and many English spas were popular then. The following letter written in $\mathrm{I} 735$ is printed by courtesy of the President and Council of the Royal College of Surgeons of England, to whom the original belongs. It discloses an early attempt at bottling natural waters for the benefit of people living at a distance from the wells. The artificial aeration of water had not yet been made practicable, and commercial bottling did not begin till the very end of the eighteenth century. This letter was written by the Rev. Stephen Hales, the versatile parson of Teddington, whose long life (I677-I76r) was given to scientific work. Dr. A. E. Clark-
Kennedy published a fascinating biography of Hales in 1929, in which may be read the full story of his many avocations, which included the demonstration and measurement of blood-pressure and the construction of novel ventilating machines for prisons and ships. Stephen Hales was a most original physiologist and a pioneer of public hygiene in that low period of English science and medicine which lies between the days of Sydenham and Boyle and those of Priestley and the Hunters. The letter is addressed to Robert Nisbit or Nesbitt, who lived from about I700 till I76r, a fashionable London physician of scientific bent. As a student at Leyden Nesbitt formed a close friendship with the great Dutch anatomist Bernard Albinus; 